\title{
Comunicação pública e jornalismo em tempos antidemocráticos
}

Por Terezinha Silva,

Daiane Bertasso e Carlos Augusto Locatelli

Professoras e professor do Programa de Pós-Graduação em Jornalismo da Universidade Federal de Santa

Catarina (PPGJOR/ UFSC).

E-mails: terezinhasilva@yahoo.

com;

daianebertasso@gmail. com; locatelli.jor@ gmail.com

Foto: Sandra Gonçalves

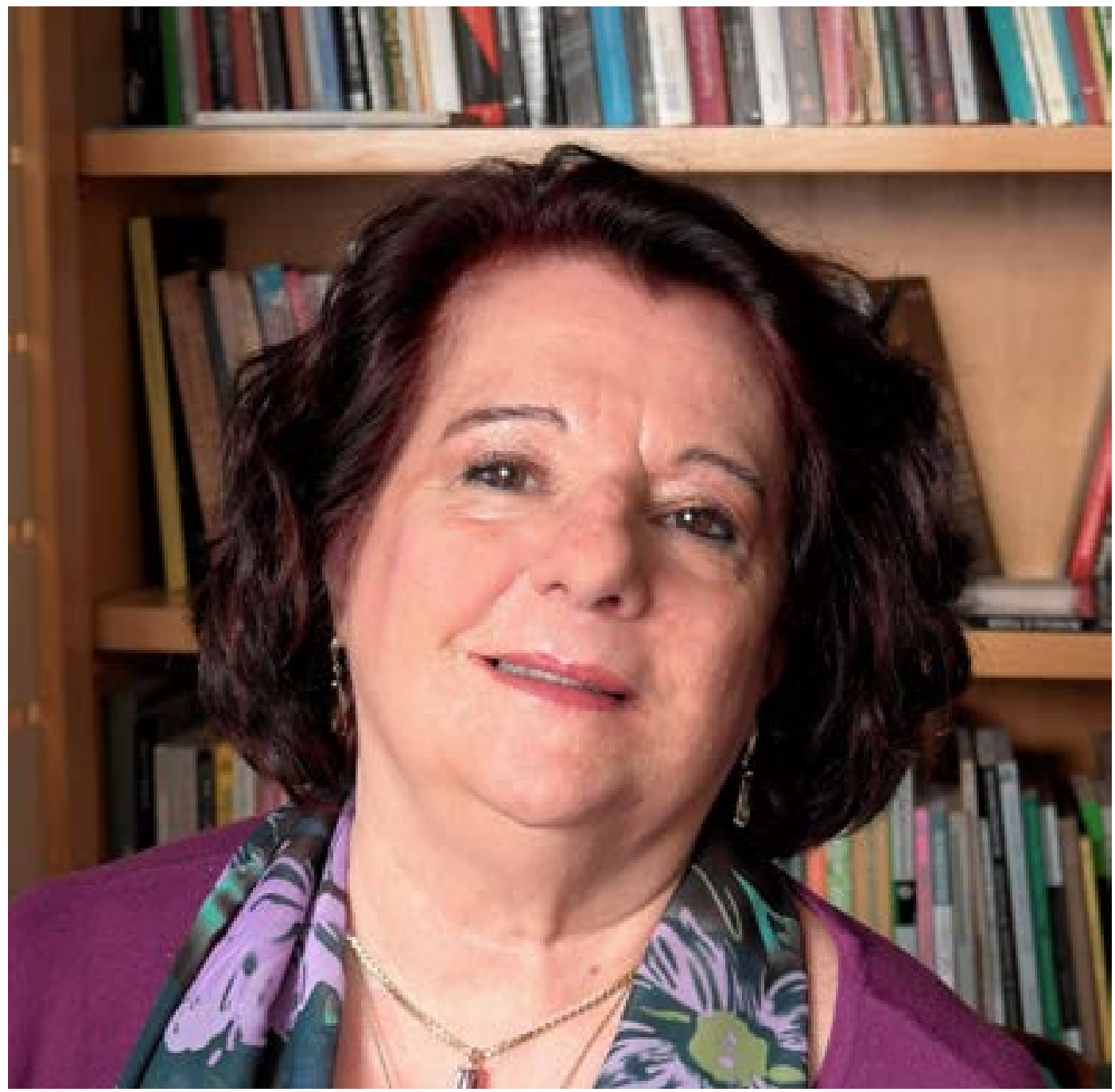

Professora, pesquisadora, escritora, intelectual, ativista, gestora pública, representante de área. Maria Helena Weber é uma mulher em luta permanente desde o início dos anos 70. Seja como estudante com posições anti-ditadura militar durante o colegial e a faculdade de Comunicação na UFRGS, seja como servidora pública da Faculdade de Biblioteconomia e Comunicação e do Programa de Pós-Graduação em Comunicação da UFRGS, como coordenadora da área de Ciências Sociais Aplicadas junto à CAPES e titular do Conselho Técnico Científico, como gestora de comunicação no Ministério da Educação, na Prefeitura de Porto Alegre e na UFRGS, ou vice-presidente da COMPÓS, diretora da Compolítica e integrante do Conselho do INCT-DD (Instituto Nacional de Ciência e Tecnologia em Democracia Digital) . Nas últimas décadas, em todos esses momentos seu foco intelectual, pesquisas e ações políticas gravitaram em torno da ampliação e garantia dos direitos civis a partir da comunicação pública, defendendo vigorosamente uma perspectiva teórica e política 
que percebe a qualidade da comunicação como indicador da qualidade da democracia. Essa vida político-acadêmica desembocou nos últimos anos em um sólido grupo de pesquisa sob sua liderança, com dezenas de participantes - alunos de graduação e pós graduação, e ex-alunos voluntários - em torno do Núcleo de Comunicação Pública e Política (NUCOP) e do Observatório de Comunicação Pública, espaços que se tornaram referência no Brasil. De sua trajetória e obra, composta por dezenas de artigos e livros, derivam um reconhecimento público e trânsito seguro - e desejavelmente controverso - entre os campos da comunicação, do jornalismo e da política. Desde 2018 a professora-pesquisadora-cidadã está cada vez mais presente no debate público, nas redes sociais, na imprensa, em bancas e conferências, defendendo agora temas sob ameaça: a comunicação pública, a universidade, a ciência, a democracia, a vida. Esta entrevista, feita por videoconferência no final de abril de 2020, registra suas percepções sobre alguns temas contemporâneos que afetam o campo científico, em particular o campo da comunicação, e, de forma ampla, a vida dos brasileiros.

\section{EJM - Você pode falar um pouco sobre o Observatório da Comunicação Pública, que você coordena? Como estão avaliando o desenvolvimento desse projeto e suas contribuições para as reflexões sobre a comunicação pública no Brasil?}

MARIA HELENA WEBER - O OBCOMP foi implantado em 2015 e é resultado de um projeto apresentado ao CNPq com investimentos da UFRGS, onde está vinculado. Aos poucos se tornou um dispositivo de comunicação e repositório de produtos e da produção sobre temas de comunicação política, governamental e a comunicação pública, sob a administração do nosso grupo de pesquisa, o NUCOP (Núcleo de Pesquisa em Comunicação Pública e Política). O OBCOMP é um dos exemplos de como a universidade pode cumprir o seu objetivo de estabelecer comunicação com a sociedade e mostrar a sua própria produção. Não é um projeto com data para terminar e esperamos que o Observatório que ele tenha uma continuidade, para além do mundo acadêmico. Exemplo disso é que alunos diretamente responsáveis pelo seu f uncionamento (mestrandos, doutorandos e bolsistas de Iniciação Científica) continuam trabalhando no Observatório mesmo depois de terminarem sua formação na UFRGS, especialmente na sua organização, garimpagem, de produtos e produção de textos. O Observatório tem uma função importante, que é a de falar à sociedade sobre um tema que não é muito simples de ser abordado como a comunicação pública, dentro do espectro da comunicação política. Um segundo aspecto é que o Observatório permite exercitar uma espécie de militância em comunicação e é nesta direção que realizamos nosso investimento intelectual e pessoal para que continue funcionando. Ainda que faça parte do Núcleo de Pesquisa em Comunicação Pública e Política, ele não reproduz exatamente as teses, dissertações e artigos científicos do NUCOP. Ele é uma outra abertura, porque as pessoas podem enviar ao Observatório comentários, artigos em modo ensaístico ou opinativo. Não tem necessariamente a ver com uma produção científica sobre comunicação pública. Temos a pretensão de estar armazenando e disponibilizando a produção científica sobre comunicação pública, além de veicular, por exemplo, campanhas de propaganda estatal, eventos científicos, debates públicos, discursos governamentais e informações sobre mídias públicas.

\section{EJM - O seu atual projeto de pesquisa estuda o processo de impeachment de Dilma Rousseff como um acontecimento público. Em que medida este acontecimento público contribuiu para o atual cenário político brasileiro?}

MARIA HELENA WEBER - A pesquisa ainda não está finalizada. Eu penso que o impeachment de Dilma Rousseff contribuiu definitivamente para fazer uma demarcação na democracia brasileira. Mostrou o grau, o poder, a incidência e o lugar garantido que os interesses privados - tanto do campo do mercado, da indústria e da 
própria mídia - possuem na construção da sociedade brasileira. Acredito que o impeachment foi surpreendente, porque não se acreditava na articulação destas forças que iniciavam ali um ardiloso Golpe que incluiria a desqualificação da esquerda, a prisão de Lula, a vitória de Bolsonaro, pode-se dizer. Não tenho condições de avaliar se ocorreu pela qualidade das políticas da Dilma; pelas novas configurações da sociedade; pelas articulações políticas, que, diferente do modo Lula de governar, não conseguiu criar um processo híbrido de participação do capital e de algumas políticas públicas importantes, como, a diminuição da miséria do povo; o investimento na educação superior e na pesquisa. A vitória acirrada de Dilma na segunda eleição é seguida por crises internas de governabilidade e o seu afastamento da ampliação de políticas sociais já iniciadas e das bases de apoio. Não sou cientista política, mas acredito que havia espaço e foi ocupado por grupos políticos estranhos ao projeto e pela direita, assim como a operação Lava Jato expunha seu partido e a palavra corrupção - até hoje - foi associada ao seu governo. Esse movimento em direção à direita já acontecia no mundo todo e o impeachment está ligado a todo esse cenário que teve a participação fundamental da imprensa. À pesquisa interessa o grau de visibilidade dado ao processo de impeachment, assim como o tipo de discursos proferidos, as disputas de poder, questões de gênero associadas e usadas para justificar a ruptura institucional. Aos poucos foi sendo revelada a hipocrisia política em diversas instituições políticas, organizações privadas e os novos movimentos sociais digitais. Esta etapa do golpe vivenciado pelo país marca o início da desqualificação autorizada da política e suas instituições e passamos a conviver com uma falta de pudor político e de relacionamento adequado para manter a democracia. O poder pós-impeachment não é um poder capaz de fortalecer a democracia. A eleição de Bolsonaro é uma consequência real. A violenta declaração de voto do então deputado Bolsonaro, para o impeachment de Dilma Rousseff, sintetizava seu caráter e, até hoje, ele é coerente e se mantém irredutível quanto ao seu entendimento de que a democracia atrapalha o

"No processo de impeachment de Dilma, a imprensa abre mão do seu desejado papel de mediação com a sociedade, para exercer seu poder como protagonista do processo". desenvolvimento nacional.

EJM - Se fosse sintetizar algo que é tão complexo, o que você considera que aquele acontecimento (o golpe contra Dilma) e seus desdobramentos (como a eleição de Jair Bolsonaro) revela da cultura política brasileira e do papel que atores com as mídias têm em relação a essa cultura e ao jogo político-democrático no país?

MARIA HELENA WEBER - O impeachment foi a parte mais contundente de um golpe para a tomada de poder e talvez a penúltima etapa tenha sido a eleição de Bolsonaro. Não sei se foi assim prevista, planejada, mas veio na sequência de 'primeiro a gente tira a Dilma'. E ainda é difícil saber o que virá, na medida em que o governo vem promovendo o desmonte das mais caras políticas públicas e enfrentando os poderes da República, sem citar suas bravatas em relação à pandemia do coronavírus no país. Enfim, o que o estrondoso acontecimento público impeachment da presidenta Dilma Rousseff mostra é que o debate público não acontece. As manifestações de rua que serviram foram aquelas em apoio ao impeachment. O próprio Estado se mostra impermeável ao debate mais amplo e democrático e, assim, não há sociedade que tenha importância. Outro aspecto importante é entender a constituição desse processo, através da imprensa. Há inúmeros estudos sobre isso, mas ressaltaria como 
fundamental que é o momento em que podemos identificar que a imprensa abre mão do seu desejado papel de mediação com a sociedade (dois lados, objetividade, etc) para exercer seu poder como protagonista do processo e, assim, abandona o espaço de interlocutora da sociedade. Fica aí uma sugestão a pesquisa para o jornalismo. Investigar o impeachment de Dilma permite analisar teorias da comunicação política e do jornalismo. Importante entender como a imprensa foi construindo aquele processo. Os editoriais dos jornais são fantásticos para esse estudo. Minha hipótese. A ver. Na sequência chegamos à vitória de Bolsonaro e seus jogos antidemocráticos e essa mesma imprensa se surpreende, e ocorre o que chamo sempre de infidelidade salutar'. A imprensa sempre volta à sua natureza. Nesse momento contribui decisivamente para a visibilidade do governo, para além das fake news, por exemplo. Assim, o jornalismo retoma um pouco o seu papel de mediação, de interlocução. Mas sem esquecer que quem construiu o cenário para a eleição de Bolsonaro foi a própria imprensa. Estamos terminando agora uma pesquisa sobre isso: as grandes questões e eixos conceituais da campanha de Bolsonaro giram em torno da construção de um inimigo, como séculos de propaganda política registram: ter um inimigo bem construído e facilmente identificável, como a esquerda, Lula e a corrupção. A imprensa registrou, por décadas, os perigos da esquerda, a fragilidade de seus governos e, finalmente, a corrupção dita 'natural'. Quando Bolsonaro se candidata, ele surfa nesse processo e seu discurso é facilmente assimilado e fortalecido pelo cenário e pelas redes digitais com as fake news.

EJM - E a imprensa demorou para se arrepender, foi dando apoio até recentemente, não?

MARIA HELENA WEBER - Eu penso que a imprensa não demorou, porque de fato nunca deu seu apoio ostensivo, à exceção de algumas redes previamente vinculadas ao apoio religioso. Bolsonaro é uma figura pouco crível; logo a imprensa não pode apostar na opinião dele, vão se afastando e outros modelos de cobertura e crítica vão sendo fortalecidos à medida que jornalistas são desqualificados. O governo Bolsonaro se fortalece com seus apoiadores na medida em que surfa no desmonte dos sistemas de comunicação pública de rádios e televisões, já iniciados na gestão Michel Temer; promove o desmonte das universidades públicas, da pesquisa e da produção cultural. O governo contribui para a valorização da mediocridade e reducionismo de problemas nacionais e isto não combina com a própria imprensa. Divulgar atos insólitos, postura ridículas e bravatas está a exigir posturas diferenciadas de cobertura e crítica. Um desafio diante das redes digitais, ainda. Estes atos "Nesse momento, a imprensa contribui para a visibilidade do governo, para além das fake news. O jornalismo retoma uim pouco o seu papel de
mediação, de interlocução". grotescos chegam até o tratamento e descaso do governo com a pandemia, surpreendendo até a imprensa internacional.

EJM - Os discursos do presidente Jair Bolsonaro desde o início da COVID-19 vão na contramão do recomendado por instituições de saúde. Ele ridiculariza a preocupação com a pandemia, desqualifica os estados brasileiros e os outros países, desautoriza a ciência. Que consequências este paradoxo do caso brasileiro provoca na comunicação pública e interesse público neste contexto social particular? 
MARIA HELENA WEBER - No âmbito da comunicação pública, a pandemia é o que se denomina acontecimento público devido a sua potência capaz de mobilizar todas as organizações políticas, governamentais e sociais. Além desta perspectiva, podemos pesquisar o que tenho classificado como o 'paradoxo da visibilidade', já que o acontecimento público traz embutido este paradoxo. Sinteticamente: de um lado, milhares de pessoas estão morrendo e o país não tem uma política nacional explícita de combate ao vírus e o governo não demonstra nenhum reconhecimento ou solidariedade ante a tragédia que assola o país. Do outro lado, mas na mesma dimensão, podemos identificar organizações e atores do mercado, da política, da mídia e da sociedade que participam de ações de solidariedade e do tratamento de questões de sobrevivência, com doações, investimentos e, assim, obtém lucros, ganhos calculados de visibilidade com a pandemia. Empresas solidárias ou resolvendo problemas empregatícios, dentre outros, vão se aliando a iniciativas de auxílio à sociedade e como tal ganham espaços como notícia e atingem milhões de pessoas. A imprensa lhes proporciona espaço de conquista de credibilidade da audiência, da sociedade àquelas empresas, produtos e marcas. Simultaneamente, estas empresas investem em publicidade para mostrar suas bondades, assim como as campanhas das próprias organizações midiáticas com esclarecimentos e indicações ocupam o lugar das campanhas governamentais. As grandes organizações estão auxiliando e investindo financeiramente para enfrentar a pandemia, mostrando que têm destinado dinheiro para hospitais, para equipamentos, para distribuir máscaras e cestas básicas etc. Mas os milhões que elas estão investindo estão sendo investidos também na sua própria imagem pública. Este acontecimento (a pandemia) permite ainda pensar que esse governo, ao contrário de outros países, não está preocupado com a sua imagem pública, com a sua reputação no campo da saúde. É um fato. Ele imprime uma insegurança. A despreocupação expressa com tudo que está ocorrendo passa a sensação de que talvez esse governo preferiria mesmo que os velhinhos, os desempregados, os pobres morressem para diminuir as estatísticas sobre a miséria no país. Então o 'paradoxo da visibilidade' permite analisar o modo como um acon-

"A pandemia permite pensar que esse governo, ao contrário de outros países, não está preocupado com a sua imagem pública". tecimento público propicia que organizações e públicos deste acontecimento participam em benefício de muitos e, também, dele se apropriem para a partição da visibilidade deste acontecimento em seu próprio benefício, em sua imagem pública.

EJM - No caso de Jair Bolsonaro, seus posicionamentos no contexto da pandemia parecem coerentes com sua trajetória de atuação, de apologia à violência, à tortura, à morte. Mas como compreender a reverberação e até aceitação desse tipo de discurso em parte da sociedade e da própria mídia brasileira?

MARIA HELENA WEBER -A pandemia acirrou o desequilíbrio político e discursivo do governo que sempre se mostrou coerente em relação à agressividade e violência propaladas na campanha de 2018. A perversidade reside no sarcasmo com que o governo minimiza os efeitos do coronavírus e deixa a sociedade à deriva; reside na manutenção do inimigo (esquerda, PT, direitos humanos, indígenas) que, segundo ele, podem ser piores do que o vírus. Ao misturar e brincar com estes conceitos com gestualidades e discursos próprios da pessoa carismática que é, investe na morte e a torna atraente. É possível desafiá-la, entendem os fanáticos e seguidores, porque o presidente garante. A morte aqui inclui a derrubada da democracia e o retorno da ditadura para promover o medo. Esta população que prefere ignorar a ciência e a democracia e 
desfraldar estas bandeiras - autorizadas pelo presidente da República - que lhes dão a segurança retirada por 'governos corruptos da esquerda', que traíram e roubaram o país. Se esse roubo é real e veraz não entra em questão. Importa a visibilidade e a divulgação dada à corrupção, prisões e condenações. Soma-se a isso, o caráter conservador e preconceituoso de parte da sociedade - tema abordado em profundidade por Lilia Schwarctz - que estava escondido, mas que foi ativado e valorizado a partir da candidatura Bolsonaro, seus exemplos e demonstrações de violência. Bolsonaro é carismático, coerente e leal ao seu grupo de parcos princípios éticos. Isto vem sendo demonstrado em toda sua história política. Nenhum desvio. Raríssimos políticos conseguem isso, porque ele acredita no que diz. O raciocínio parece ser 'se ele acredita no que diz e ele é meu presidente, eu vou segui-lo'. Até a morte. Facilmente se chegou ao fanatismo, ao apoio sob quaisquer circunstâncias. São pessoas aptas a praticar qualquer violência contra os outros e contra si mesmo, como demonstra a reação à pandemia. O caótico discurso após a demissão do ministro da Justiça, Sérgio Moro, em 24 de abril, não é diferente de todas as lives e todos os discursos que ele fez na campanha. Essa coerência é fundamental para o público que adora Bolsonaro. Então, são muitos aspectos implicados. Bolsonaro vai agregar o brasileiro eleitor que não precisa mais ter pudor e pode se colocar ao lado da violência, da ignorância, da mediocridade, qualquer que seja sua classe. E, por fim, mais um elemento na tentativa de compreender a pulsão de ódio e morte, especialmente, em relação à pandemia. Seus eleitores dizem 'ele pode ser doido, mas está fazendo alguma coisa e eu não posso não apoiá-lo’. Para esse eleitor, não apoiar mais Bolsonaro significa também admitir que foi ludibriado. Se o eleitor gosta de votar em quem está ganhando não pode admitir que foi enganado, que se deixou enganar. Pela primeira vez esses eleitores foram protagonistas de uma campanha eleitoral com sua própria mídia, através de fake news, boatos etc.

EJM - E qual a responsabilidade de instituições importantes para a democracia (imprensa, justiça etc) na escalada neoconservadora no Brasil? Não há um vale tudo em termos de ação e de expressão que não são questionadas pelas instituições e que afrontam a própria democracia?

MARIA HELENA WEBER - A liberdade de expressão é defensável mesmo que fale contra a democracia. Ela é necessária à democracia. Imagino que as instituições tenham mecanismos de impedir que se promova ações e discursos anticonstitucionais, considerados criminosos. No entanto, estamos convivendo com eventos antidemocráticos e contrários à proteção dos cidadãos contra o coronavírus e... nada sucede, além de discursos. Qual é o limite das ações do Poder Judiciário e mesmo do Legislativo em relação à postura e consequências dos discursos subjacentes sobre a morte e o retorno à ditadura? Aguardemos. A questão não é a liberdade de expressão, a questão é onde se está fazendo a apologia a um crime, ou ao nazismo, ou à ditadura. É este movimento simbólico que precisa ser, de alguma maneira, criminalizado. O silêncio deve ser rompido.
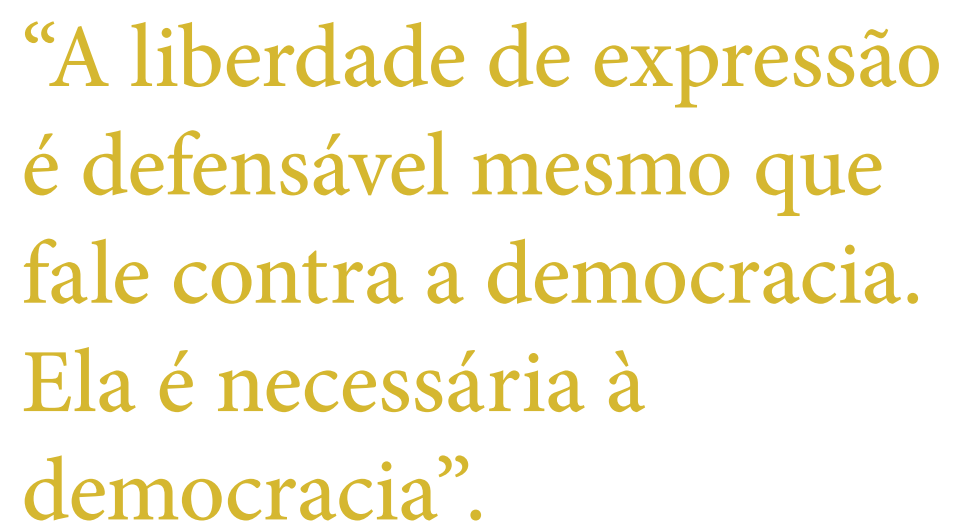

EJM - Em seus trabalhos sobre imagem pública, você observa bem que ela é o resultado de disputas simbólicas. Agora, na disputa Jair Bolsonaro versus Sérgio Moro, é possível antever como pode se reconfigurar a imagem pública dessas duas figuras políticas? E, sobretudo, qual lugar ocupará a mídia hegemônica nesta disputa, considerando que ela foi determinante para projetar esses dois atores na cena política do país? 
MARIA HELENA WEBER - O discurso dos dois atores do Poder Executivo mostra o que ambos querem preservar na imagem pública deles. Em Bolsonaro, um pai traído pelo filho adotado e investido de confiança, embora soubesse que era uma adoção problemática. Moro, por sua vez, foi traído por este presidente que tudo prometeu e não cumpriu. Moro entrou na burocracia governamental, com a reputação da Lava Jato, mas arranhou sua imagem pública ao abandonar sua carreira de juiz. Além disso, sua trajetória está eivada de acusações, de posturas questionáveis, de deslizes éticos e gramaticais. A força era da Operação Lava Jato e não dele. Por isso utilizo reputação e imagem. Aqui reside a sua fragilidade, talvez, na disputa com o presidente da República. Ao perscrutarmos a imagem de Moro veremos críticas e oscilações quanto à coerência e legalidade de suas ações como juiz. Bolsonaro, como venho dizendo nesta entrevista, sempre não surpreende, é coerente e bate nas mesmas teclas, embora mostre sinais de desequilíbrio e inconsistência. É o presidente e tem poder, mesmo que as pesquisas de opinião mostrem relevante apoio a Moro. Neste momento, incidem sobre a imagem pública dos dois a dúvida sobre quem diz a verdade e esta imagem, então, está bastante fragilizada, no sentido de que a opinião pública pode avaliá-los e dizer 'este está mentindo muito, este um pouco mais'. Enfim, eles não parecem confiáveis sobre o tema em questão. Neste momento, as dúvidas recaem mais sobre Bolsonaro do que Moro. O Executivo está fragmentado, definido como irresponsável em relação às orientações da OMS (Organização Mundial da Saúde) para enfrentar a pandemia e com dificuldades de abordar um plano econômico. Moro como acusador e vítima leva um pouco de vantagem pois se contrapõe ao presidente como muitas das instâncias judiciais e legislativas Moro pode querer defender-se como o 'corajoso em busca de sua ética" num governo desorganizado e desequilibrado, que coloca o país em perigo constante.

EJM - Em relação à contribuição do Jornalismo para a Comunicação Pública, nota-se que o jornalismo contemporâneo tem a possibilidade de utilizar dados públicos a partir da Lei da Transparência e da Lei de Acesso à Informação. Você acredita que o jornalismo, inserido neste ambiente digital, utiliza potencialmente essas ferramentas e consegue mediar o interesse público?

MARIA HELENA WEBER - Sobre essa abertura de dados, eu acabei de orientar

"Se hoje não há um jornalismo de qualidade, talvez os motivos não estejam na busca ou acesso à informação, mas em uma tese, recentemente, da Marlise Brenol [Transparência digital e Jornalismo]. Nunca as instituições estiveram tão expostas quanto atualmente e a quantidade de dados e informações disponibilizadas é ampla. Certamente o acesso aos dados públicos permite um jornalismo profundamente vinculado ao interesse público, como raramente conseguiu. Embora seja da sua natureza se dirigir ao interesse público [tese de Basílio Sartor], nem sempre o jornalismo tem dados para abordar temas em sua amplitude. Assim, se hoje não há um jornalismo de qualidade, talvez os motivos não estejam exatamente na busca ou acesso à informação, mas em interesses editoriais. Talvez nos falte mais pesquisas que acompanhem historicamente o comportamento dos jornais ou da imprensa e o gradativo acesso a esses dados públicos. Isso é algo relevante porque hoje rapidamente é possível acompanhar o que está acontecendo e, ao mesmo tempo, a quantidade de informações e a fragmentação inerente dificulta para qualquer pessoa ter acesso à totalidade, cotejar o que está sendo dito e onde deverá buscar. Jean Baudrillard, em 
um dos livros da década de 1980, sobre estratégias fatais, mostra que a quantidade de informações é uma dessas estratégias. Ele fala da "obesidade", da incapacidade que temos de decodificar, de metabolizar todas essas informações. Hoje, em função dos próprios sistemas de produção e circulação de informações, as pessoas vão se conformando ao fragmento. Temos aí um outro paradoxo, gosto desse termo porque ele é chave. Por um lado, pode-se ter acesso a uma infinidade de informações; por outro, dedica-se apenas à informação preferencial, ao pedaço. Se eu recebo um jornal impresso em casa, a tendência é eu passar por todas as páginas e editorias. Se eu acesso as informações em meio digital, a minha tendência é ficar com um tipo de informação apenas. Nesse ambiente, penso que as perigosas e sedutoras fake news podem evoluir ainda mais, ou seja, um pedaço de informação pode ser transformado, ampliado e vai passando adiante, de modo autoral. Para o debate público, nunca houve uma possibilidade tão importante quanto esta com o amplo acesso a dados e mídias. Por outro lado, esses meios, pela própria dinâmica da democracia, não são usados em todas as suas possibilidades. Os leitores se detêm em um título, em uma charge etc. e transformam esse fragmento em algo que seria a totalidade. Penso que o papel do jornalismo estaria exatamente no modo como ele sintetiza essa totalidade que é do interesse público.

EJM - Ainda a respeito de transparência e direito do cidadão à informação sobre os assuntos que os afetam, como você avalia a comunicação do governo com a sociedade e a própria relação entre Bolsonaro e imprensa? Imprensa que contribuiu para a construção do cenário que o levou ao poder, como você disse antes. Mais recentemente imprensa e jornalistas são atacados e desrespeitados por ele. Como você avalia essa tensão e contradição na relação entre eles?

MARIA HELENA WEBER - O desprezo que esse governo tem pela democracia se reflete no desprezo que ele tem pela imprensa, pelos jornalistas. Na perspectiva de Bolsonaro, não existem versões que a imprensa possa dar porque existe apenas uma verdade: a dele. Na recorrente citação da Bíblia sobre a 'verdade que nos salvará', ele tenta legitimar seus discursos sobre qualquer assunto. Na verdade, ele não faz um discurso político, não dialoga, não responde aos jornalistas, mas sua fala é publicitária. Continua em campanha e neste sentido afronta o jornalismo. Neste sentido, esse governo vem provando que não está interessado com a comunicação e relações com a sociedade, ou seja, as condições para uma comunicação pública não existem

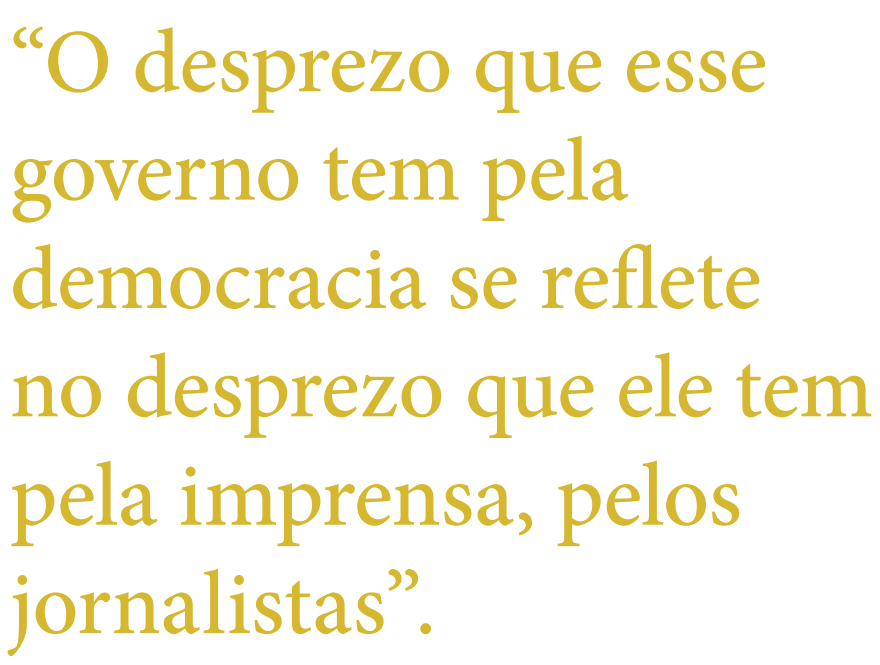
em sua totalidade. Se a imprensa não está dizendo exatamente o que ele quer, esta imprensa está dizendo mentiras, na sua concepção. Ele consegue dizer e se desdizer num mesmo texto, e depois inverte e diz que quem disse foi a imprensa. Não tem o menor pudor político e a conduta de um presidente democrático. Por outro lado, o desmonte da EBC (Empresa Brasileira de Comunicação) e da rede de TVs públicas no Brasil dá uma ideia do quanto este governo está disposto a fazer propaganda e muito pouco interessado em jornalismo e em cultura. Há uma tensão salutar toda vez que se divulga que o governo está dizendo algo sobre a imprensa e a imprensa reage àquela crítica. Quando ele desqualifica a Globo porque esta estaria fazendo a campanha de Sérgio Moro ou vice-versa, não vem ao caso agora, acaba sendo um tiro no pé. Porque não se pode desprezar uma emissora que tem uma audiência de milhões e milhões de pessoas. Pode-se até criticá-los, mas o presidente não pode desqualificar ou não entender o papel de uma emissora desse tipo. A tensão vai aumentar. Se ele pudesse instituir uma censura, ele o faria. 
Mas não pode, por enquanto. O desrespeito aos jornalistas equivale ao desrespeito aos poderes Judiciário e Legislativo. Perguntas se amontoam nesta discussão, do tipo: deveriam os jornalistas esperar pelas migalhas discursivas no cercadinho do Palácio? Como não fazer a cobertura do governo, do presidente? Enfim, bons tempos para a pesquisa.

EJM - Em entrevista ao jornal Le Monde em abril de 2020, o filósofo Jurgen Habermas diz que a ciência não deve temer o crescimento do pensamento científico ultraconservador no campo acadêmico, pois ele é fraco, pobre e não resiste ao próprio debate. Mas deve temer o pensamento ultraconservador ao nível do senso comum, pois ele desconstitue o pensamento científico. Qual sua percepção sobre essa assertiva, especificamente no caso da comunicação?

MARIA HELENA WEBER - O pensamento científico conservador ou ultraconservador, quer seja sobre a questão da pandemia, da terra plana, das questões de gênero, meio ambiente e outras coisas absurdas se mantêm no senso comum, porque são facilmente compreensíveis e amparadas em preconceitos, moralismos e religiosidades. O problema é maior quando essas ideias são institucionalizadas e defendidas em instâncias de poder e, portanto, são defensáveis por pessoas ignorantes e seduzidas pela facilidade de compreender. É difícil para a maioria das pessoas discernir as subjetividades do campo político ou comunicacional expressas em discursos e atitudes e entender o significado do que está acontecendo no governo. Nos nossos grupos e meios é fácil entender brincadeiras, ironias, mas do ponto de vista do senso comum não é. Veja o caso da saída de Sérgio Moro do governo. É simplesmente uma demissão? É uma exoneração? Não, não é. Isso nos

"A comunicação pública é uma dimensão normativa das democracias [...]. A qualidade da democracia também se mede pela qualidade da comunicação pública”. leva a pensar a que tipo de informação as pessoas têm acesso para compreender o mundo? Penso ser necessário um modo pedagógico de explicar o mundo e quem tem poder e interpretá-lo para que possa ser melhor compreendido. Só o sistema educacional pode oferecer caminhos a esta compreensão, assim como a imprensa tem um papel importante, mas não consegue cumprir sozinha este papel. O discurso simplificado, fácil, o discurso populista, isto sim a sociedade apreende bem facilmente. Se alguém diz 'os comunistas vão tomar o poder e ocuparão sua casa', e se este alguém é o meu presidente ou o meu ministro, eu vou acreditar, porque quem é mais importante que ele? Sempre há as disputas de verdades discursivas entre a política, a religião, a lei, o cientista, o professor e o jornalista. Como acessar? Se não há informações suficientes é possível minar absolutamente tudo que está sendo dito. Enfim, penso que Habermas tem razão. Mas qual é a ruptura disto? De que maneira a sociedade pode se fazer ouvir? Bem, ainda temos as redes sociais, vários tipos de esfera pública, temos a possibilidade de falar pelas instituições. Mas eu não sou tão otimista assim. A perspectiva do interesse público vem sendo submetida aos interesses privados cada vez mais, assim como as democracias são submetidas ao capitalismo. No caso específico do senso comum a respeito da comunicação, embora o trabalho do pesquisador no campo da comunicação esteja cada vez mais sofisticado, ao contrário de outros campos os resultados não aparecem em nenhum dos grandes meios de comunicação. Então, nós pesquisamos para as prateleiras e para os nossos próprios alunos. Ou seja, se os resultados das pesquisas não chegam ao jornalismo, não chegam ao senso comum. 
EJM - Os estudos sobre comunicação pública viveram um boom nos últimos 20 anos. Coincidentemente, os últimos 20 anos foram marcados, de forma geral, pela eleição de gestores públicos com perspectivas mais democráticas sobre a informação e comunicação. A perspectiva política de cada momento tende a afetar a percepção dos estudos sobre o potencial e os limites da comunicação pública?

MARIA HELENA WEBER - A comunicação pública tem três níveis importantes: sistemas, políticas e discurso do Estado. Os sistemas de comunicação pública estão estruturados para fazer o papel de intermediário entre o governo, a sociedade e a própria mídia. O papel destes veículos é pedagógico. No caso das emissoras de televisão, elas sempre foram mal administradas do ponto de vista desta função. A EBC tentou resgatar isso. Recentemente, especialmente a partir do governo Temer, esses sistemas de comunicação de Estado têm sido desmontados. Quando o governo tira a $E B C$ da cobertura e coloca em seu lugar a $N B R$ você tem uma emissora que faz o que o governo quer, faz propaganda e se afasta do interesse público. Então, estamos numa fase muito mais de propaganda do que qualquer tipo de cobertura. Um segundo nível seriam as estruturas burocráticas de comunicação pública que operacionalizam políticas de comunicação através de relações e produção de comunicação entre o governo e a sociedade que estabelecem participação e diálogo. Qual é o espaço que vem sendo dado às relações, às audiências, os materiais, as oitivas, enfim, para que esta sociedade se faça ouvir em torno de temas de seu interesse? Pode-se afirmar que campanhas de propaganda são apenas uma das partes desta comunicação pública. O governo federal demonstra pouco interesse na comunicação pública própria da democracia. Num terceiro nível estaria o próprio discurso do Estado em defesa do interesse público, porque isto é uma democracia, mas o conceito - interesse público - também vem sendo relativizado. Podemos identificar, de modo consistente a passagem da definição de comunicação governamental para comunicação pública sediada no conceito de esfera pública e opinião pública que, associada a outras perspectivas, indicam que a comunicação do governo não é necessariamente pública. A comunicação pública tem uma relação direta com a democracia, com aquilo que é público, assim o discurso dos governos democráticos deve privilegiar o interesse público e isto se sobrepõe, obviamente, a interesses privados. O governo Bolsonaro demarca seu discurso por interesses privados. A comunicação pública é uma dimensão normativa das democracias e identificar sua abrangência e "A universidade precisa abrigar o limitações significa expor de que modo a democracia de um estado está sendo qualificada ou não. A qualidade da democracia também se mede pela qualidade da comunicação pública. Se há um desaparecimento desta comunicação pública, o que pode acontecer? Nunca os governos tiveram tantos meios, tantas estruturas para fazer comunicação, para estabelecer canais de comunicação, para pesquisar, para ouvir. Mas talvez nunca se tenha feito tão pouca comunicação pública. Temos que estudar isso. Penso que a atuação do governo brasileiro no período pós-Dilma oferece elementos extremamente substantivos para novas perspectivas de pesquisa, que tem a ver com as possibilidades de um governo de regime democrático não executar os princípios da comunicação pública. Esse assunto é de grande complexidade porque, aparentemente, há uma comunicação executada ininterruptamente e é pública porque é visível a todos. Mas, não.

EJM - Dada a configuração do sistema de mídia brasileiro e suas vinculações com os campos político, religioso e econômico e a crescente polarização da sociedade, que arenas restam para conduzir o debate público e reduzir a própria polarização?

MARIA HELENA WEBER - Uma saída para abrigar o debate público está na uni- 
versidade. A universidade precisa abrigar o debate público; precisa repensar de que maneira ela pode se abrir e colocar em discussão temas que são caríssimos a respeito da evolução do país, da sociedade e das democracias. Seja no campo da comunicação, da genética, da sociologia, do direito e de todas as ciências. Devemos pensar de que maneira poderemos criar estas relações com a sociedade e traduzir este conhecimento, contribuindo para um debate necessário. A imprensa participa e centraliza alguns debates sobre temas de interesse público, mas tornou-se um ator político interessado. Os leitores vão para os sites de jornais à procura de jornalistas específicos, de forma fragmentada porque a comunicação tornou-se totalmente fragmentada. Essa é uma característica da televisão, mas tornou-se característica de toda a imprensa e das nossas relações. $\mathrm{O}$ fragmento é tudo que vamos ler. Então, temos este desafio, como fazer o debate público? A Universidade pública é o caminho e tem disponíveis tecnologias, dispositivos informacionais e a produção científica capaz de promover a interação entre universidade e sociedade. Acredito que o Observatório de Comunicação Pública é um exemplo disso, assim como inúmeros eventos e debates que expõem a produção da universidade e atraem audiência.

EJM - Na sua experiência enquanto pesquisadora principalmente das áreas de comunicação política e de comunicação pública, qual a sua avaliação em relação à efetividade do potencial desses dois tipos de práticas de comunicação nas organizações e instituições públicas brasileiras, em especial no que se refere ao alcance do interesse público?

MARIA HELENA WEBER - Quando não se tem uma política de comunicação pública determinada pelo governo, que é onde ela começa, as instituições não se sentem obrigadas ou consideram que sequer precisam pensar a respeito. Então acaba sendo muito mais uma política de assessoria de imprensa ou de propaganda. É algo que tem acontecido bastante. É muito mais a promoção da instituição, dos próprios governantes, dos dirigentes, do que o estabelecimento de relações com a sociedade. É muito complexo fazer uma comunicação pública, porque exige planejamento e muito trabalho para estabelecer essas relações, mas isso deve ser perseguido como objetivo, pois é uma das maneiras importantes para fortalecer a democracia. 